\title{
Factors influencing patient's choice of type of surgery: Laparoscopic vs Open
}

\author{
SYED MUHAMMAD BILAL ${ }^{1}$, WASIM HAYAT KHAN ${ }^{2}$, USMAN ISMAT BUTT ${ }^{3}$, ROSHAN BUTT $^{4}$, MUHAMMAD UMAR $^{5}$, \\ MALIK RAMZAN KASHIF \\ ${ }_{1,3,5}$ Assistant Professor of Surgery, SIMS/Services Hospital, Lahore \\ ${ }^{2}$ Professor of Surgery, SIMS/Services Hospital, Lahore \\ ${ }^{4}$ PGR, Department of Surgery, SIMS/Services Hospital, Lahore \\ ${ }^{6}$ Senior Registrar Surgery, SIMS/Services Hospital, Lahore \\ Correspondence to Dr Syed Muhammad Bilal, Email : bilalshah12@hotmail.com, Contact: 0333-4259662
}

\begin{abstract}
Aim: To evaluate the preference of patients presenting to a government sector hospital in Lahore regarding type of gall bladder surgery.

Methodology: A cross sectional observation study was conducted at the Department of General Surgery, Services Hospital, Lahore from 1st January 2020 to $30^{\text {th }}$ June 2021. A simple questionnaire to collect and analyze the data of the patients admitted for cholecystectomy. The content of the questionnaire included sociodemographic characteristics and lists of factors for making choice regarding type of surgery by the patient. Data was entered and analyzed using EXCEL 2013. Frequencies and Percentages were calculated as descriptive statistics whereas Fisher's exact test was conducted as inferential statistics.

Results: The results of our study showed that the age $(p=0.0001)$ of patient and cost $(p=0.0427)$ of surgery played the most significant role in patient's decision regarding the type of surgery.

Conclusion: Age of the patient and financial constraints are important factors when patients decide about the type of surgery they want have. Despite advantages of laparoscopic surgery many patients chose open surgery due to poor financial status.
\end{abstract}

Keywords: Cholecystectomy, type of surgery, patient's choice, factors

\section{INTRODUCTION}

Gallstones are hard deposits that form in the gall bladder due to various factors. The size, shape and constitution of these stones may vary. ${ }^{1}$ Gallstones are a common phenomenon in the modern age $^{2}$. But they have been troubling humans since the start of written history 3,4 . Some geographical variations in gallstone prevalence have been seen $^{5}$. Incidence of gallstones increases with age ${ }^{6}$ and women are much more likely to develop them ${ }^{7}$. Most of the cases are asymptomatic. Only $10 \%$ of the patients develop symptoms $^{8,9}$. In the western world almost $10-15 \%$ of the population is believed to suffer from the condition ${ }^{10}$. Each year $1-2 \%$ of patients develop symptoms or complications. ${ }^{11}$ Studies from Pakistan also reveal a similar trend with almost $10-20 \%$ of the population showing the presence of gall stones ${ }^{12,13,14}$.

Cholecystectomy is performed for the removal of the gall bladder. There are many indications for the removal of the gall bladder with gall bladder stones being one of the most common ones. Gall bladder removal may be undertaken via open or laparoscopic approach. Laparoscopic cholecystectomy is a minimally invasive surgical procedure for removal of gallbladder. It was introduced in the early 1990s and has since almost replaced the open technique ${ }^{15}$. A large number of studies have compared these two approaches ${ }^{16,17,18,19}$. Although the complication rate for both the approaches are similar it has been shown that the laparoscopic approach is

Received on 13-03-2021

Accepted on 04-08-2021 associated with less operative blood loss, less postoperative pain, less post-operative infections, a shorter hospital stay and early return to routine life ${ }^{20}$.

With the introduction of laparoscopic techniques in the western world, laparoscopic cholecystectomy was also introduced in Pakistan in the early 1990's. Since then it has gradually been adopted by most of the general surgeons and is now one of the most commonly performed elective procedures $^{21}$. As the benefits of laparoscopic surgery outweigh those of open surgery the decision for surgeon and patient to make regarding type of surgery is straightforward 22 .

The health care system of our country and specifically Punjab may be considered to have two sectors. Government based free surgeries are offered for all but there may be a considerable waiting time. Private based surgeries whose cost may vary widely but offer early surgery with hardly any waiting times ${ }^{23,24}$.

We were curious as to how the patients chose their surgeries and if the patient was to bear the cost himself would monetary issues be a factor that influenced the decision? In this regard we carried out this study to evaluate the reasons for patient's choice of surgery.

The objective of the study was to evaluate the preference of patients presenting to a government sector hospital in Lahore regarding type of gall bladder surgery.

\section{MATERIAL AND METHODS}

We carried out a cross-sectional observation study at the Department of General Surgery, Services Hospital, Lahore from $1^{\text {st }}$ January 2020 to $30^{\text {th }}$ June 2020. We recruited patients by Non-probability, consecutive sampling. All 
patients of either gender and of any age who had been admitted for cholecystectomy were included in the study. Patients who refused to give consent for inclusion in study were excluded from the study. Informed consent for inclusion was taken from all participants. Approval from the hospital Ethical committee was also taken before the start of the study.

We designed a simple questionnaire to collect and analyze the data of the patients. All patients were interview using the questionnaire. Information regarding both types of procedures was provided to the patients. Bio data of patients and their responses to the questions were recorded. All data was entered into EXCEL and analyzed. Quantitative variables like age and education level are presented as mean and standard deviation while frequency and percentages are used for gender and choice of type of surgery. Analysis of the reason for their choice was done. Post-stratification Fischer's exact test used and $p$ value equal or less than 0.05 taken as significant.

\section{RESULTS}

A total of 200 patients were included in our study. Out of them $15 \%$ (30) were male while $85 \%(170)$ were female. The mean age of the patients was 42.46 years. $24.5 \%$ (49) patients were illiterate while the rest were literate. When stratification of variables was done to evaluate the reason of choice of surgery it was seen that the age of patient and cost of surgery played the most significant role. Older patients were more likely to opt for open surgery. Similarly, when patients were asked regarding their choice of surgery if they had to pay themselves for the surgeries a significant portion opted for open surgery. Results are summarized in Table 1.

Table 1: Summary of results

\begin{tabular}{|c|c|c|c|}
\hline \multicolumn{4}{|c|}{ Age of patients } \\
\hline \multicolumn{4}{|l|}{42.46 years } \\
\hline \multicolumn{4}{|c|}{ Gender distribution } \\
\hline Male & \multicolumn{2}{|l|}{30} & $15 \%$ \\
\hline Female & \multicolumn{2}{|l|}{170} & $85 \%$ \\
\hline \multicolumn{4}{|l|}{ Education } \\
\hline Illiterate & \multicolumn{2}{|l|}{49} & $24.5 \%$ \\
\hline Literate & \multicolumn{2}{|l|}{151} & $75.5 \%$ \\
\hline \multicolumn{4}{|c|}{ Stratification of decision regarding surgery } \\
\hline & Free(Govt) & Self & \multirow{3}{*}{$\begin{array}{l}\text { Fisher's exact test } \\
\text { The two-tailed } P \text { value } \\
\text { equals } 0.0427\end{array}$} \\
\hline Laparaoscopy & 164 & 79 & \\
\hline \multirow[t]{2}{*}{ Open } & 36 & 121 & \\
\hline & Female & Male & \multirow{3}{*}{$\begin{array}{l}\text { Fisher's exact test } \\
\text { The two-tailed } P \text { value } \\
\text { equals } 0.2820\end{array}$} \\
\hline Laparaoscopy & 151 & 21 & \\
\hline \multirow[t]{2}{*}{ Open } & 29 & 7 & \\
\hline & Illiterate & Literate & $\begin{array}{l}\text { Fisher's exact test } \\
\text { The two-tailed } P \text { value } \\
\text { equals } 0.2001\end{array}$ \\
\hline Laparaoscopy & 37 & 127 & \\
\hline \multirow[t]{2}{*}{ Open } & 12 & 24 & \\
\hline & $<40$ years & $\begin{array}{l}>40 \\
\text { years }\end{array}$ & \multirow{3}{*}{$\begin{array}{l}\text { Fisher's exact test } \\
\text { The two-tailed } P \text { value is } \\
\text { less than } 0.0001\end{array}$} \\
\hline Laparaoscopy & 96 & 68 & \\
\hline Open & 7 & 29 & \\
\hline
\end{tabular}

\section{DISCUSSION}

A total of 200 patients who were admitted with gall bladder stones were interviewed by us. A majority of them were women $(85 \%)$. This is in line with the fact that gallstones are especially common in women. Furthermore, the average age of our patient was 42.26 years. The same has been demonstrated all over the world that the gall bladder stones are more common after middle age. ${ }^{10,25}$

When asked for their choice of surgery the majority of patients wished to get laparoscopic surgery $(82 \%)$. This is largely due the fact that the advantages of laparoscopic surgery are not just documented in the various academic studies but also known to the general population as well. Similar findings were also noted by other researchers. ${ }^{26,27,28}$

When we stratified the data for variables effecting the decision of the patients regarding the type of surgery they wanted it was seen that there was no significant relationship between gender or education of the patient and decision regarding surgery. Age of the patient was however significantly co-related to the decision. Older patients(>40years) were much more likely to opt for open surgery as compared to the younger patients. ( $<40$ years). Age of the patient has been shown to effect the decision making of the physicians ${ }^{29,30}$ and it has also been reported to effect the patient's own decision making. ${ }^{31,32,33}$

Similarly, the cost of surgery also played a significant impact on the type of surgery opted by the patient. Although the majority of patients wished to have laparoscopic when offered with free surgery the decision changed dramatically when they were asked to consider their options if they had to pay for their own surgery. Despite the many advantages of laparoscopic surgery due to the involved disposables and gadgetry the cost of laparoscopic surgery as compared to open is higher. This difference was enough to dissuade the majority of the patients from laparoscopic surgery. Similar tradeoffs have also been reported in studies conducted in other parts of the world when patients had to decide between financial resources and healthcare ${ }^{34,35,36}$

Our study has a number of limitation. It is a single center study. It has a small study population with the majority of patients belonging to lower and lower- middle class. Perhaps if patients belonging to upper class were also to be included the results might be different. Furthermore, we questioned our participants only regarding an elective procedure, perhaps similar study about emergency procedure may yield different results.

\section{CONCLUSION}

On the basis of our results, we conclude that the age of the patient and the financial constraints are important factors when patients decide about the type of surgery they want have. Despite advantages of laparoscopic surgery many patients chose open surgery due to poor financial status.

\section{REFERENCES}

1. Channa NA, Khand FD, Khand TU, Leghari MH, Memon AN. Analysis of human gallstone by fourier transform infrared (FTIR) Pak J Med Sci. 2007;23:546-50.

2. Bouchier TA. Gallstones. Proc R Soc Med. 1977;70:597-9.

3. Berci G. Historical overview of surgical treatment of biliary stone disease. In: MacFadyen BV, Arregui M, Eubanks S, Olsen DO, Peters JH, Soper NJ, et al., editors. Laparoscopic Surgery of the Abdomen. New York: Springer; 2004. pp. 13942. 
4. Gordon-Taylor G. On gallstones and their sufferers. $\mathrm{Br} \mathrm{J}$ Surg. 1937;25:241-51.

5. Njeze GE. Gallstones. Niger J Surg. 2013;19(2):49-55. doi:10.4103/1117-6806.119236

6. Shaffer EA. Gallstone disease: Epidemiology of gallbladder stone disease. Best Pract Res Clin Gastroenterol. 2006;20:981-96.

7. Dray X, Joly F, Reijasse D, Attar A, Alves A, Panis Y, et al. Incidence, risk factors, and complications of cholelithiasis in patients with home parenteral nutrition. J Am Coll Surg. 2007;204:13-21.

8. Thistle JL, Cleary PA, Lachin JM, Tyor MP, Hersh T. The natural history of cholelithiasis: The National Cooperative Gallstone Study. Ann Intern Med. 1984;101:171-5.

9. Friedman GD, Raviola CA, Fireman B. Prognosis of gallstones with mild or no symptoms: 25 years of follow-up in a health maintenance organization. $\mathrm{J}$ Clin Epidemiol. 1989;42:127-36.

10. Stinton LM, Shaffer EA. Epidemiology of gallbladder disease: cholelithiasis and cancer. Gut Liver. 2012;6:172-187.

11. Friedman GD. Natural history of asymptomatic and symptomatic gallstones. Am J Surg. 1993;165:399-404.

12. BHATTI, Amna Younas et al. A cross sectional study on the risk factors of gallbladder stone. International Journal of Research in Medical Sciences, [S.I.], v. 4, n. 11, p. 5041 5046, dec. 2016. ISSN 2320-6012. Available at: <https://www.msjonline.org/index.php/ijrms/article/view/319>. Date accessed: $14 \quad$ aug. 2021. doi:http://dx.doi.org/10.18203/2320-6012.jjrms20163814.

13. Jadoon S, Nawaz M, Javed S, Imtiaz H, Jadoon O, Taimoor A. Study On The Prevalence Of Gallstones In Patients Undergoing Cholecystectomy In Benazir Bhutto Shaheed Hospital (DHQ) Abbottabad. J Ayub Med Coll Abbottabad. 2021 Jan-Mar;33(1):102-104. PMID: 33774963.

14. Bilal, Muhammad \& Haseeb, Abdul \& Saad, Muhammad \& Raza, Madiha \& Ahmed, Aafia \& Shahnawaz, Waqas \& Ahmed, Bilal \& Motiani, Vanita. (2016). The Prevalence and Risk Factors of Gallstone among Adults in Karachi, South Pakistan: A Population-Based Study. Global Journal of Health Science. 9. 106. 10.5539/gjhs.v9n4p106.

15. Kapoor T, Wrenn SM, Callas PW, Abu-Jaish W. Cost Analysis and Supply Utilization of Laparoscopic Cholecystectomy. Minim Invasive Surg. 2018;2018:7838103.

16. Keus F, de Jong J, Gooszen HG, Laarhoven CJHM. Laparoscopic versus open cholecystectomy for patients with symptomatic cholecystolithiasis. Cochrane Database of Systematic Reviews 2006, Issue 4. Art. No.: CD006231. DOI: 10.1002/14651858.CD006231. Accessed 14 August 2021.

17. Coccolini F, Catena F, Pisano M, Gheza F, Fagiuoli S, Di Saverio S, Leandro G, Montori G, Ceresoli M, Corbella D, Sartelli M, Sugrue M, Ansaloni L. Open versus laparoscopic cholecystectomy in acute cholecystitis. Systematic review and meta-analysis. Int J Surg. 2015 Jun;18:196-204. doi: 10.1016/j.ijsu.2015.04.083. Epub 2015 May 6. Erratum in: Int J Surg. 2015 Dec;24(Pt A):107. PMID: 25958296.

18. Antoniou SA, Antoniou GA, Koch OO, Pointner R, Granderath FA. Meta-analysis of laparoscopic vs open cholecystectomy in elderly patients. World J Gastroenterol. 2014;20(46):1762617634. doi:10.3748/wjg.v20.i46.17626

19. Steffens, D., Wales, K., Toms, C. et al. What surgical approach would provide better outcomes in children and adolescents undergoing cholecystectomy? Results of a systematic review and meta-analysis. Ann Pediatr Surg 16, 24 (2020). https://doi.org/10.1186/s43159-020-00032-0

20. Novitsky YW, Kercher KW, Czerniach DR, et al. Advantages of Mini-laparoscopic vs Conventional Laparoscopic Cholecystectomy: Results of a Prospective Randomized Trial.
Arch Surg. 2005;140(12):1178-1183. doi:10.1001/archsurg.140.12.1178.

21. Ali A, Chawla T, Jamal A. Ambulatory laparoscopic cholecystectomy: Is it safe and cost effective?. J Minim Access Surg. 2009;5(1):8-13. doi:10.4103/0972-9941.51314.

22. Amin A, Haider MI, Aamir IS, et al. Preoperative and Operative Risk Factors for Conversion of Laparoscopic Cholecystectomy to Open Cholecystectomy in Pakistan. Cureus. 2019;11(8):e5446. Published 2019 Aug 20. doi:10.7759/cureus.5446

23. http://www.emro.who.int/pak/programmes/servicedelivery.html

24. Shaikh BT. PRIVATE SECTOR IN HEALTH CARE DELIVERY: A REALITY AND A CHALLENGE IN PAKISTAN. J Ayub Med Coll Abbottabad. 2015 Apr-Jun;27(2):496-8. PMID: 26411151

25. Novacek G. Gender and gallstone disease. Wien Med Wochenschr. 2006 Oct:156(19-20):527-33. doi: 10.1007/s10354-006-0346-x. PMID: 17103289.

26. Mohamad Irani, Cheruba Prabakar, Sepide Nematian, Nitasha Julka, Devika Bhatt, Pedram Bral, "Patient Perceptions of Open, Laparoscopic, and Robotic Gynecological Surgeries", BioMed Research International, vol. 2016, Article ID 4284093, 6 pages, 2016. https://doi.org/10.1155/2016/4284093.

27. Kluivers KB, Opmeer BC, Geomini PM, et al. Women's preference for laparoscopic or abdominal hysterectomy. Gynecol Surg. 2009;6(3):223-228. doi:10.1007/s10397-0080455-1.

28. Çelik, A, Aksu, M, Özkan, N , Ersoy, F , Kayaoğlu, H . (2009). Patient knowledge and perception on laparoscopic cholecystectomy: a questionnaire based study for optimizing informed consent . Cumhuriyet Medical Journal , 31 (4) , 374387 Retrieved from https://dergipark.org.tr/en/pub/cmj/issue/4211/55768

29. Anandan, P., \& Sivakumar, S. (2020). An assessment of the factors affecting surgical decision making: a multi institutional study. International Surgery Journal, 7(4), 1138-1142. doi:http://dx.doi.org/10.18203/2349-2902.isj20201388

30. L. Fraenkel, N. Rabidou, R. Dhar, Are rheumatologists' treatment decisions influenced by patients' age?, Rheumatology, Volume 45, Issue 12, December 2006, Pages 1555-1557, https://doi.org/10.1093/rheumatology/kel144

31. Song MK, Ward SE. The extent of informed decision-making about starting dialysis: does patients' age matter?. J Nephrol. 2014;27(5):571-576. doi:10.1007/s40620-014-0061-4.

32. David G. Li, Fan Di Xia, Jasmine Rana, Grace J. Young, Forootan Alizadeh, Cara Joyce, Shinjita Das, Arash Mostaghimi, "Factors Influencing Patient Decisions Regarding Treatments for Skin Growths: A Cross-Sectional Study", Dermatology Research and Practice, vol. 2018, Article ID 3941347, 4 pages, 2018. https://doi.org/10.1155/2018/3941347

33. DeVoe JE, Wallace LS, Fryer GE Jr. Patient age influences perceptions about health care communication. Fam Med. 2009;41(2):126-133.

34. Nguyen OK, Higashi RT, Makam AN, Mijares JC, Lee SC. The Influence of Financial Strain on Health Decision-Making. J Gen Intern Med. 2018;33(4):406-408. doi:10.1007/s11606017-4296-3

35. Hajjaj FM, Salek MS, Basra MK, Finlay AY. Non-clinical influences on clinical decision-making: a major challenge to evidence-based practice. J R Soc Med. 2010;103(5):178-187. doi:10.1258/jrsm.2010.100104

36. Ubel PA. Beyond costs and benefits: understanding how patients make health care decisions. Oncologist. 2010;15 Suppl 1:5-10. doi: 10.1634/theoncologist.2010-S1-5. PMID: 20237210. 